\title{
MicroRNA-25-3p regulates human nucleus pulposus cell proliferation and apoptosis in intervertebral disc degeneration by targeting Bim
}

\author{
ZHIFANG ZHAO, JIE ZHENG, YOUCHEN YE, KEFENG ZHAO, RUOZHANG WANG and RAN WANG
}

Department of Orthopedics, No. 903 Hospital of People's Liberation Army, Hangzhou, Zhejiang 310013, P.R. China

Received June 18, 2019; Accepted February 25, 2020

DOI: $10.3892 / \mathrm{mmr} .2020 .11483$

\begin{abstract}
Intervertebral disc degeneration (IDD) is a degenerative disease of the spine originating from the intervertebral disc. MicroRNAs (miRNAs or miRs) are a group of endogenous small non-coding RNAs that act on target genes and play a critical role in numerous biological processes. However, the underlying mechanism of miR-25-3p in IDD remains unclear. Therefore, the present study aimed to explore the role of miR-25-3p in the pathogenesis of IDD. The results demonstrated that miR-25-3p was downregulated in rat degenerative nucleus pulposus (NP) cells and that Bcl-2 interacting mediator of cell death (Bim) was a direct target of miR-25-3p. Next, to investigate the effect of miR-25-3p on normal NP cell proliferation and apoptosis, NP cells were transfected with an miR-25-3p inhibitor, a negative control of miR-25-3p inhibitor, miR-25-3p inhibitor + control-small interference RNA (siRNA) or miR-25-3p inhibitor + Bim-siRNA for $48 \mathrm{~h}$ and cell proliferation and apoptosis were then analyzed. The results demonstrated that the miR-25-3p inhibitor could decrease NP cell proliferation and induce cell apoptosis, and these effects were reversed by Bim-siRNA.In addition, an in vitro cell model of IDD was established by subjecting $\mathrm{NP}$ cells to $10 \mathrm{ng} / \mathrm{ml}$ interleukin (IL)-1 $\beta$ for $24 \mathrm{~h}$. Further experiments suggested that IL-1 $\beta$ treatment induced a reduction in NP cell proliferation and an increase in cell apoptosis, which were prevented by the miR-25-3p mimic. All the effects of miR-25-3p mimic on IL-1 $\beta$-treated NP cells were significantly reversed by Bim upregulation. These findings suggested that miR-25-3p may be a novel therapeutic target for IDD prevention.
\end{abstract}

\section{Introduction}

Intervertebral disc degeneration (IDD) is a degenerative disease of the spine originating from the intervertebral disc, leading

Correspondence to: Dr Ran Wang, Department of Orthopedics, No. 903 Hospital of People's Liberation Army, 14 Lingyin Road, Hangzhou, Zhejiang 310013, P.R. China

E-mail: wangran1159@163.com

Key words: intervertebral disc degeneration, Bcl-2 interacting mediator of cell death, miR-25-3p, apoptosis to instability of the spine, disc herniation, spinal stenosis and cervical spondylosis. IDD is one of the most important causes of musculoskeletal disability and leads to the wide presence of motor dysfunction in the population worldwide (1).

Since the pathogenesis of IDD is not fully understood, current treatments are limited and tend to focus on pain relief rather than inhibiting disease progression. The main pathological changes in IDD are nucleus pulpocyte apoptosis and excessive degradation of extracellular matrix (ECM) (2). The expression of type II collagen and proteoglycan, which are originally expressed in normal nucleus pulposus tissue, is upregulated, while the expression of type I collagen is increased, during intervertebral disc degeneration (3). Type I collagen was significantly different due to its biomechanical characteristics (4). The increase in content of ECM leads to changes in the biomechanical properties of the disc, which can cause the development of IDD (5).

A number of studies have been conducted on the role of microRNAs (miRNAs or miRs) in various diseases (6-8). miRNAs are a general term for a class of small-molecule non-coding RNAs that are 20-22 nucleotides in length, as opposed to mRNA-transcribed proteins. miRNAs do not encode proteins, but inhibit the expression of multiple target genes by binding to the 3 '-untranslated region (3'-UTR) of target mRNAs (9-11). There is increasing evidence that miRNAs may be involved in the development and progression of various diseases, such as cardiovascular disease, cancer and autoimmune diseases (6-8). Previous study has demonstrated that miR-25-3p can regulate the proliferation and apoptosis of cancer cells in a variety of cancer types and is closely associated with the degradation of human nucleus pulposus cells (12).

$\mathrm{Bcl}-2$ interacting mediator of cell death (Bim) is a member of the BH3 subfamily of the Bcl-2 family (13). It is an important regulatory protein of apoptosis and is stable in the homeostasis of hematopoietic cells, preventing autoimmunity and tumorigenesis (14). Bim is widely expressed in normal cells and exists in a variety of isomers (15). Certain apoptotic stimuli can activate Bim molecules through various signaling pathways (16). Activated Bim molecules activate Bax through interaction with Bcl-2/Bax, causing apoptosis via the mitochondrial pathway (17). Bim is closely associated with the development and treatment of autoimmune diseases, degenerative diseases and tumors (18). Therefore, basic research into the role of Bim 
in apoptosis should provide the theoretical basis and insights for clinical treatment.

The present study aimed to investigate the role of miR-25-3p in the pathogenesis of IDD and to explore the underlying mechanism.

\section{Materials and methods}

IDD rat model establishment. According to a previous study, a total of 20 healthy male Wistar rats (300-350 g; aged 14-16 weeks; Model Animal Research Center Of Nanjing University, Nanjing, China) were selected. All rats were housed under standard conditions at room temperature $\left(22-24^{\circ} \mathrm{C}\right)$ and humidity $(60-65 \%)$ on a 12 -h light/dark cycle with ad libitum supply of food and water. A rat IDD model was established by puncture method (19). First, the rats were anesthetized with an intraperitoneal injection of $3 \%$ sodium pentobarbital $(40 \mathrm{mg} / \mathrm{kg})$. Following anesthesia, the limbs were fixed and placed on the operating table. X-ray angiography of the rats was performed using a Faxitron instrument (Faxitron X-ray Corporation) to identify the segments of the lumbar vertebrae. Then, according to the angiographic results, the 3-4 lumbar intervertebral discs of the rats were selected. After determining the position, the needle of the lumbar vertebra (coccygeal intervertebral levels Co6-7 and Co8-9) was pierced with a $20-\mathrm{ml}$ needle to cause degeneration of the intervertebral disc by mechanical damage. After 2 weeks, the extent of disc degeneration in the experimental rats was determined using magnetic resonance imaging. The health and behavior of all rats were monitored every 2 days. No rats died during the experiments. Experiment was ended when the rats lost $>15 \%$ of their body weight. Rats were anesthetized with pentobarbital $(40 \mathrm{mg} / \mathrm{kg})$ and then sacrificed by cervical dislocation, with death defined as the lack of heartbeat and breathing. All experimental procedures were performed in accordance with the Recommended Guideline for the Care and Use of Laboratory Animals issued by the Chinese Council on Animal Research (20). The current study was approved by the Animal Ethics Committee of the No. 903 Hospital of People's Liberation Army (approval no. IRB SOP/01.03/01.1).

Isolation and culture of primary degenerative nucleus pulposus (NP) cells. After the IDD model was established successfully, the model and control rats were anesthetized with pentobarbital by intraperitoneal injection, their limbs were fixed and the prosthesis was placed on the operating table. The skin and lumbar vertebrae were cut, the cells were separated from NP tissue and medium was added to prepare a single cell suspension. Then, the cells were purified by differential adherent culture to obtain primary degenerative NP cells. Following successful primary culture in Dulbecco's modified Eagle's medium (DMEM, Invitrogen; Thermo Fisher Scientific, Inc.) containing 10\% fetal bovine serum (FBS, Invitrogen; Thermo Fisher Scientific, Inc.) at $37^{\circ} \mathrm{C}$ for $24 \mathrm{~h}$, the cells were stained with hematoxylin and eosin at room temperature for $15 \mathrm{~min}$ and morphological identification of NP cells was carried out by observing the morphology and aggregation of the cells under an inverted phase contrast microscope (IX51; Olympus Corporation).
IDD in vitro cell model establishment. To establish the IDD in vitro cell model, normal NP cells were treated with $10 \mathrm{ng} / \mathrm{ml}$ interleukin (IL)-1 $\beta$ for $24 \mathrm{~h}$. Untreated NP cells were used as control cells.

Cell transfection. Normal NP cells were transfected with a miR-25-3p inhibitor (5'-UCAGACCGAGACAAGUGCAAU G-3'; Guangzhou RiboBio Co., Ltd.), the negative control (NC) of miR-25-3p inhibitor (5'-CAGUACUUUUGUGUAGUA CAA-3'; Guangzhou RiboBio Co., Ltd.), miR-25-3p inhibitor + control-small interference (siRNA) (cat no. sc-36869; Santa Cruz Biotechnology, Inc.), miR-25-3p inhibitor + Bim-siRNA (cat no. sc-29802; Santa Cruz Biotechnology, Inc.), miR-25-3p mimic (sense, 5'-CAUUGCACUUGUCUCGGUCUGA-3' and anti-sense, 5'-UCAGACCGAGACAAGUGCAAUG-3'; Santa Cruz Biotechnology, Inc.), mimic control (sense, 5'-UUUGUA CUACACAAAAGUACUG-3' and anti-sense, 5'-CAGUAC UUUUGUGUAGUACAAA-3'; Guangzhou RiboBio Co.,Ltd.), miR-25-3p mimic + control-plasmid (cat no. sc-437275; Santa Cruz Biotechnology, Inc.) or miR-25-3p mimic + Bim-plasmid (cat no. sc-419332-ACT; Santa Cruz Biotechnology, Inc.) using Lipofectamine $2000^{\circledR}$ reagent (Invitrogen; Thermo Fisher Scientific, Inc.) for $48 \mathrm{~h}$ following the manufacturer's protocol. At $48 \mathrm{~h}$ post-transfection, the transfection efficiency was detected using reverse transcription-quantitative PCR (RT-qPCR).

$R T-q P C R$. Cell total RNA $\left(5 \times 10^{6}\right.$ cells) was extracted using the TRIzol ${ }^{\circledR}$ (Invitrogen; Thermo Fisher Scientific, Inc.) according to the manufacturer's protocol. The total RNA concentration was detected by NanoDrop 2000 spectrophotometer (NanoDrop Technologies; Thermo Fisher Scientific, Inc.). Total RNA was stored at $-80^{\circ} \mathrm{C}$ for further use. The synthesis of cDNA was carried out with the RevertAid ${ }^{\mathrm{TM}}$ First Strand cDNA Synthesis kit (Thermo Fisher Scientific, Inc.). qPCR was performed using the cDNA by SYBR RT-PCR kit (Takara Bio, Inc.) according to the manufacturer's protocol. qPCR was performed as follows: $10 \mathrm{~min}$ at $95^{\circ} \mathrm{C}$, followed by 35 cycles of $15 \mathrm{sec}$ at $95^{\circ} \mathrm{C}$ and $40 \mathrm{sec}$ at $55^{\circ} \mathrm{C}$. The primer sequences used for RT-qPCR were: miR-25-3p, forward, 5'-CATTGCACTTGTCTCGGTCTGA-3' and reverse, 5'-GCT GTCAACGATACGCTACGTAACG-3'; U6, forward, 5'-CTC GCTTCGGCAGCACA-3' and reverse, 5'-AACGCTTCA CGAATTTGCGT-3'; Bim, forward, 5'-CACAAACCCCAA GTCCTCCT-3' and reverse, 5'-ACACCAGGCGGACAATGT AA-3'; caspase-3, forward, 5'-TGTCGATGCAGCAAACCT CA-3' and reverse, 5'-GACTTCTACAACGATCCCCTC-3'; Bax, forward, 5'-CGTCCACCAAGAAGCTGAGCG-3' and reverse, 5'-CGTCCACCAAAGCTGAGCG-3'; Bcl-2, forward, 5'-TTGGATCAGGGAGTTGGAAG-3' and reverse, 5'-TGT CCCTACCAACCAGAAGG-3'; SOX-9, forward, 5'-GTACCC GCACTTGCACAAC-3' and reverse, 5'-TCGCTCTCGTTC AGAAGTCTC-3'; proteoglycan (ACAN), forward, 5'-TTG TGACTCTGCGGGTCATC-3' and reverse, 5'-GTCCCTAGG AGGGCCTTCAG-3'; collagen I, forward, 5'-GGCGGCCAG GGCTCCGACCC-3' and reverse, 5'-AATTCCTCGTCTGGG GCACC-3'; collagen II, forward, 5'-ATGGCGGCTTCCACT TCAG-3' and reverse, 5'-CGGTGGCTTCATCCAGGTAG-3'; and GAPDH, forward, 5'-TGCACCACCAACTGCTTAGC-3' and reverse, 5'-GGCATGGACTGTGGTCATGAG-3'. Relative 
expression levels were calculated using the $2^{-\Delta \Delta \mathrm{Cq}}$ method (21) following normalization to the expression of GAPDH or U6. All experiments were performed in triplicate.

Western blot assay. NP cells were washed 3 times with pre-cooled PBS and total cellular protein was extracted using a modified RIPA buffer (Beyotime Institute of Biotechnology) containing $1 \mathrm{mM}$ PMSF for $30 \mathrm{~min}$. A BCA protein quantitative kit (Thermo Fisher Scientific, Inc.) was applied to detect protein concentration. The proteins (40 $\mu \mathrm{g}$ per lane) were separated by $10 \%$ SDS-PAGE and transferred to PVDF membranes. The membranes were blocked with $5 \%$ non-fat milk at room temperature for $2 \mathrm{~h}$, followed by incubation with primary antibodies against Bcl-2 (cat no. 4223; 1:1,000; Cell Signaling Technology, Inc.), Bax (cat no. 5023; 1:1,000; Cell Signaling Technology, Inc.), Bim (cat no. 2933; 1:1,000; Cell Signaling Technology, Inc.), cleaved caspase-3 (cat no. 9661; 1:1,000; Cell Signaling Technology, Inc.), pro-caspase-3 (cat no. ab183179; 1:1,000; Abcam), caspase-3 (cat no. 9662; 1:1,000; Cell Signaling Technology, Inc.), SOX-9 (cat no. ab185230; 1:1,000; Abcam), ACAN (cat no. ab36861; 1:1,000; Abcam), collagen I (cat no. ab34710; 1:1,000; Abcam), collagen II (cat no. ab239007; 1:1,000; Abcam) and GAPDH (cat no. 5174; 1:1,000; Cell Signaling Technology, Inc.) overnight for $4^{\circ} \mathrm{C}$. The membrane was then incubated for $2 \mathrm{~h}$ at room temperature with a secondary antibody (horseradish peroxidase-conjugated anti-rabbit immunoglobulin $\mathrm{G}$; cat no. 7074; 1:2,000; Cell Signaling Technology, Inc.). Proteins were detected using SignalFire ${ }^{\mathrm{TM}}$ enhanced chemiluminescence reagent (cat. no. 6883; Cell Signaling Technology, Inc.) and imaged. GAPDH was used as an internal control. Band densities were quantified using Gel-Pro Analyzer densitometry software (version 6.3; Media Cybernetics, Inc.).

MTT assay. MTT assay was performed to detect cell proliferation. Following treatment, the cells were inoculated in a 96-well plate with $1 \times 10^{4}$ cells per well and incubated in a $37^{\circ} \mathrm{C}, 5 \% \mathrm{CO}_{2}$ incubator. Then, $20 \mu 15 \mathrm{mg} / \mathrm{ml}$ MTT agent (Sigma-Aldrich; Merck KGaA) was added to cells. Following incubation for $4 \mathrm{~h}$, the formazan crystals were dissolved in $150 \mu \mathrm{l}$ DMSO (Sigma-Aldrich; Merck KGaA). The absorbance was measured at a wavelength of $490 \mathrm{~nm}$ using a microplate reader.

Flow cytometry assay. The cells were collected in logarithmic growth phase by trypsinization, washed 3 times with PBS and trypsinized into single cell suspensions. Apoptotic cells were detected using the Annexin V FITC/PI apoptosis detection kit (BD Biosciences; Becton, Dickinson and Company) according to the manufacturer's protocol. The cells were stained with Annexin V-FITC and propidium iodide (PI) for $15 \mathrm{~min}$ in the dark at room temperature. Finally, flow cytometry (BD Biosciences; Becton, Dickinson and Company) was used to detect cell apoptosis and the data were analyzed using FlowJo software (version 7.6.1; FlowJo LLC).

Dual luciferase reporter assay. Bioinformatics software (TargetScan 7.2, http://www.targetscan.org/vert_72/) was used to predict the target gene of miR-25-3p. The results revealed the binding sites between the 3'-UTR of Bim and miR-25-3p. To confirm the association between miR-25-3p and Bim, a luciferase reporter containing the 3'-UTR sequence of Bim was constructed using pmiR-RB-Report ${ }^{\mathrm{TM}}$ Dual-Luciferase reporter gene plasmid vector (Guangzhou RiboBio Co., Ltd.) according to the manufacturer's protocol. Cells seeded in 24-well plates were cotransfected with miR-25-3p mimic or mimic control and the mutant (MUT) or wild type (WT) 3 '-UTR of Bim using Lipofectamine $2000^{\circledR}$ (Invitrogen; Thermo Fisher Scientific, Inc.) for $48 \mathrm{~h}$, together with Renilla luciferase pRL-TK vector as a control. Following transfection for $48 \mathrm{~h}$, the cells were lysed with RIPA buffer (Beyotime Institute of Biotechnology). The relative luciferase activity was detected using the Dual-Luciferase Reporter Assay System (Promega Corporation) according to the manufacturer's protocol.

Statistical analysis. Every experiment was performed $\geq 3$ times. All data are shown as the mean \pm standard deviation. The significance of differences between two groups was measured using the Student's t-test. Differences between multiple groups were detected using one-way ANOVA followed by Tukey's test. Data analyses were performed using GraphPad Prism 6.0 (GraphPad Software, Inc.). $\mathrm{P}<0.05$ was considered to indicate a statistically significant difference.

\section{Results}

Expression of miR-25-3p and IDD markers in rat NP cells. In order to detect the expression of IDD markers and miR-25-3p in rat NP cells, RT-qPCR and/or western blotting were performed to compare the expression levels of ACAN, collagen I, collagen II, SOX-9 and miR-25-3p in degenerative and non-degenerated NP cells. The RT-qPCR results demonstrated that miR-25-3p was expressed reduced in rat degenerative NP cells compared with that in normal NP cells (Fig. 1A). In addition, IDD-associated markers, including ACAN, collagen I, collagen II and SOX-9 were highly expressed in rat degenerative NP cells (Fig. 1B-F).

Bim is a direct target of $m i R-25-3 p$. Next, to determine the targets of miR-25-3p, TargetScan analysis was performed. TargetScan revealed that the 3'-UTR of Bim mRNA contains a putative site that is partially complementary to miR-25-3p (Fig. 2A). Furthermore, a luciferase reporter assay was performed to examine whether miR-25-3p interacted directly with the target gene Bim. The luciferase activity in NP cells transfected with Bim-WT and miR-25-3p mimic was decreased compared with that in NP cells transfected with Bim-WT and mimic control. However, no significant difference was observed in the luciferase activity of NP cells transfected with Bim-MUT and miR-25-3p mimic and that of NP cells transfected with Bim-MUT and mimic control (Fig. 2B). Taken together, these results demonstrated that Bim was the direct target gene of miR-25-3p.

Effect of miR-25-3p downregulation on the proliferation and apoptosis of normal NP cells. In order to evaluate the role of miR-25-3p downregulation in normal NP cells, NP cells were transfected with the miR-25-3p inhibitor, miR-25-3p inhibitor $\mathrm{NC}$, inhibitor + control-siRNA or inhibitor + Bim-siRNA. The results revealed that the miR-25-3p inhibitor significantly decreased the level of miR-25-3p in NP cells (Fig. 3A), while 
A

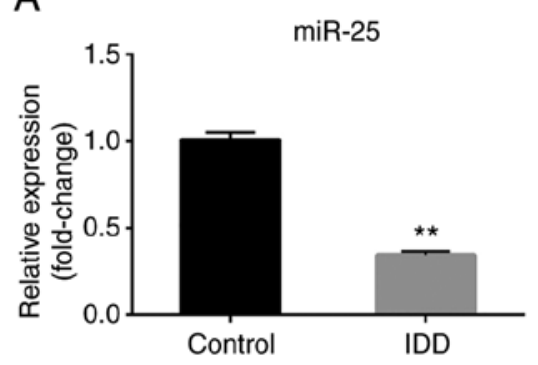

B Control IDD

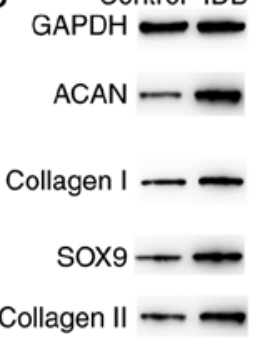

C

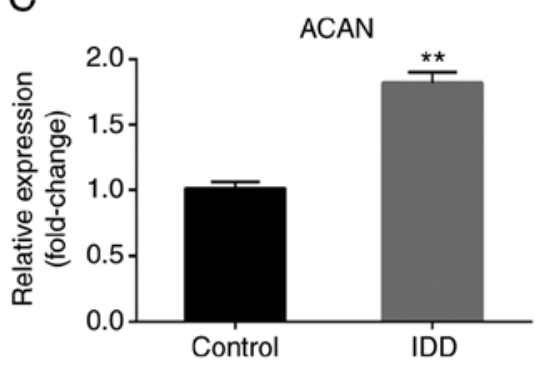

$\mathrm{F}$

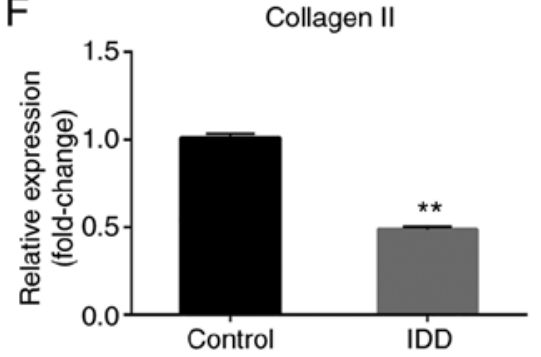

Figure 1. Expression of miR-25-3p and IDD markers in rat NP cells. (A) RT-qPCR assay detected the relative expression of miR-25-3p. (B) Western blot assay detected the protein expression of ACAN, collagen I, collagen II and SOX-9. (C-F) RT-qPCR assay detected the relative mRNA expression of ACAN, collagen I, SOX-9 and collagen II. Control, NP cells from control rats; IDD, NP cells from rats with IDD. ${ }^{* *}$ P<0.01 vs. control. miR, microRNA; IDD, intervertebral disc degeneration; RT-qPCR, reverse transcription-quantitative PCR; NP, nucleus pulposus; ACAN, proteoglycan.

\section{A Bim wild $\quad 5^{\prime} \quad$...UUGCCACUUUACUUGUGCAAUA... hsa-miR-25 $3^{\prime}$ AGUCUGGCUCUGUUCACGUUAC Bim mutant $5^{\prime}$...UUGCCACUUUACUUCAAACCGA...}

B

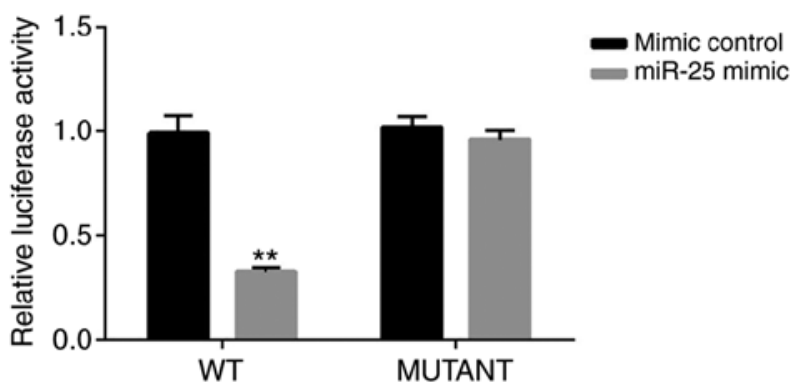

Figure 2. Bim is the direct gene of miR-25-3p. (A) TargetScan predicted Bim 3'-UTR binding sites for miR-25-3p. (B) miR-25-3p mimics or mimic control and wild type or mutant Bim 3'-UTR were co-transfected into nucleus pulposus cells. Luciferase activity was detected by a dual luciferase reporter assay. ${ }^{* *} \mathrm{P}<0.01$ vs. mimic control. miR, microRNA; UTR, untranslated region; Bim, Bcl-2 interacting mediator of cell death; WT, wild type.

Bim-siRNA significantly reduced the mRNA level of Bim in NP cells (Fig. 3B). Then, the effect of miR-25-3p on the proliferation of NP cells was explored. An MTT assay indicated that when the cells were transfected with miR-25-3p inhibitor, the cell viability was decreased compared with the control (Fig. 3C). To further determine the apoptotic effect of miR-25-3p, flow cytometry was performed to detect cell apoptosis. Flow cytometry analysis demonstrated that transfection with the miR-25-3p inhibitor significantly induced NP cell apoptosis (Fig. 3D and E). All the effects of miR-25-3p inhibitor on NP cells were reversed by Bim-siRNA.
Effect of miR-25-3p downregulation on the expression level of Bim and apoptosis-associated molecules in normal NP cells. To further verify the role of miR-25-3p on NP cell apoptosis, western blot assay and RT-qPCR were performed to detect the expression of $\mathrm{Bim}$ and apoptosis-associated proteins (Bax, Bcl-2, caspase-3, cleaved caspase-3 and pro-caspase-3). The results demonstrated that miR-25-3p inhibitor significantly enhanced the protein expression of Bim, Bax, cleaved caspase- 3 and caspase-3, while Bcl-2 and pro-caspase- 3 protein expression was downregulated (Fig. 4A). Similar results were obtained with RT-qPCR (Fig. 4B-E). All the effects of miR-25-3p inhibitor on NP cells were reversed by Bim-siRNA.

miR-25-3p upregulation inhibits the effects of $I L-1 \beta$ stimulation on normal NP cells. The effect of miR-25-3p on IL-1 $\beta$-stimulated NP cells was explored. The results indicated that miR-25-3p mimic significantly increased the level of miR-25-3p in NP cells (Fig. 5A) and Bim-plasmid significantly enhanced the mRNA level of Bim in NP cells (Fig. 5B). miR-25-3p upregulation significantly enhanced the viability of NP cells, which IL-1 $\beta$-reduced (Fig. 5C) and reduced IL-1 $\beta$-induced NP cell apoptosis (Fig. 5D and E), These changes were reversed by the Bim-plasmid. miR-25-3p upregulation markedly decreased IL-1 $\beta$-enhanced expression of Bim, Bax, cleaved caspase- 3 and caspase- 3 , and increased IL-1 $\beta$-reduced expression of Bcl-2 and pro-caspase-3 (Fig. 6). These changes were reversed by Bim-plasmid.

\section{Discussion}

IDD is the main cause of lower back pain and is a medical condition that constitutes a heavy burden on the global medical 

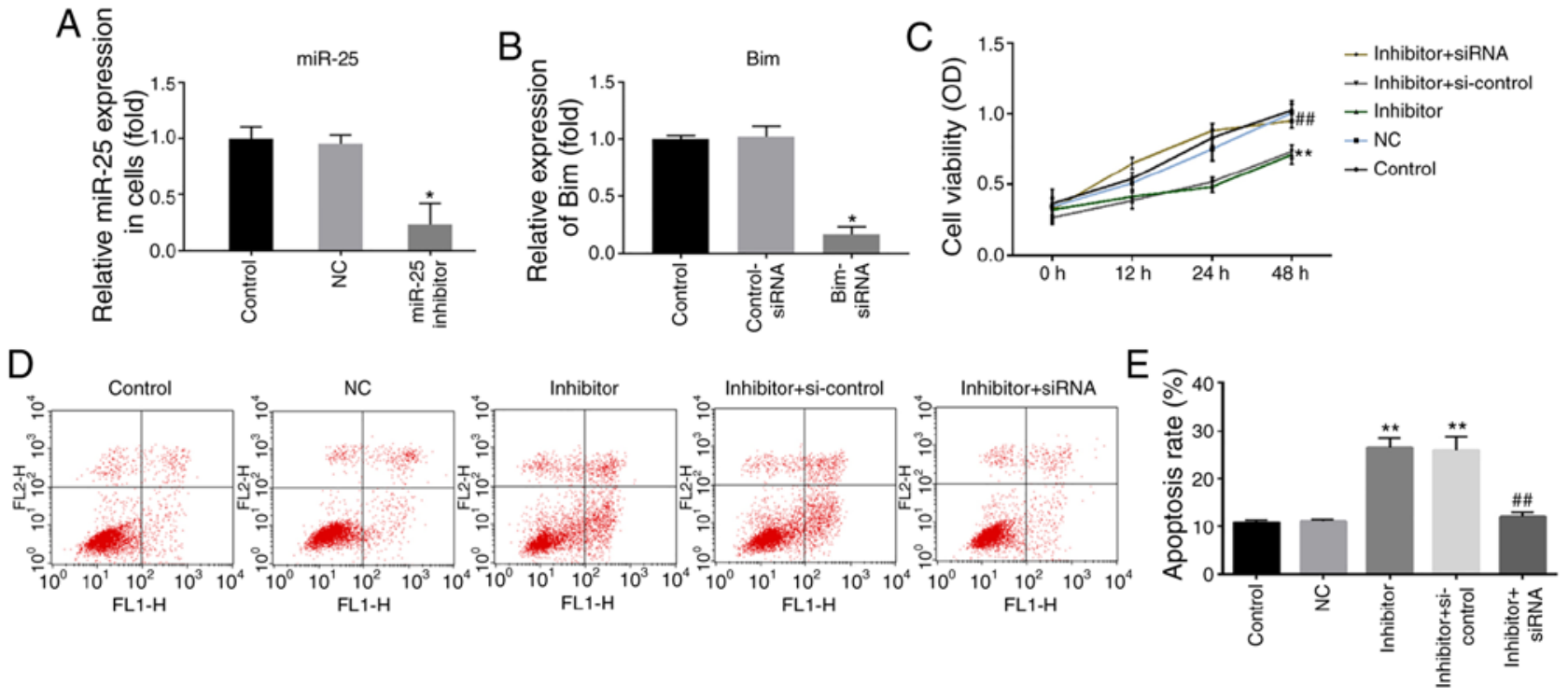

Figure 3. Effect of miR-25-3p downregulation on the proliferation and apoptosis of NP cells. (A) The level of miR-25-3p in NP cells was detected using RT-qPCR. (B) The mRNA level of Bim in NP cells was detected using RT-qPCR; (C) MTT assay detected the cell viability of NP cells. (D) Flow cytometry assay and (E) analysis measured the apoptosis of NP cells. Control, NP cells without any treatment; NC, NP cells transfected with the NC of miR-25-3p inhibitor; miR-25-3p inhibitor/inhibitor, NP cells transfected with miR-25-3p inhibitor; control-siRNA, NP cells transfected with control-siRNA; Bim-siRNA, NP cells transfected with Bim-siRNA; inhibitor + si-control, NP cells transfected with miR-25-3p inhibitor and control-siRNA; inhibitor + siRNA, NP cells transfected with miR-25-3p inhibitor and Bim-siRNA. ${ }^{*} \mathrm{P}<0.05$ and ${ }^{* *} \mathrm{P}<0.01$ vs. control; ${ }^{\# *} \mathrm{P}<0.01$ vs. inhibitor + si-control. miR, microRNA; NP, nucleus pulposus; RT-qPCR, reverse transcription-quantitative PCR; Bim, Bcl-2 interacting mediator of cell death; NC, negative control; si, small interfering; OD, optical density.
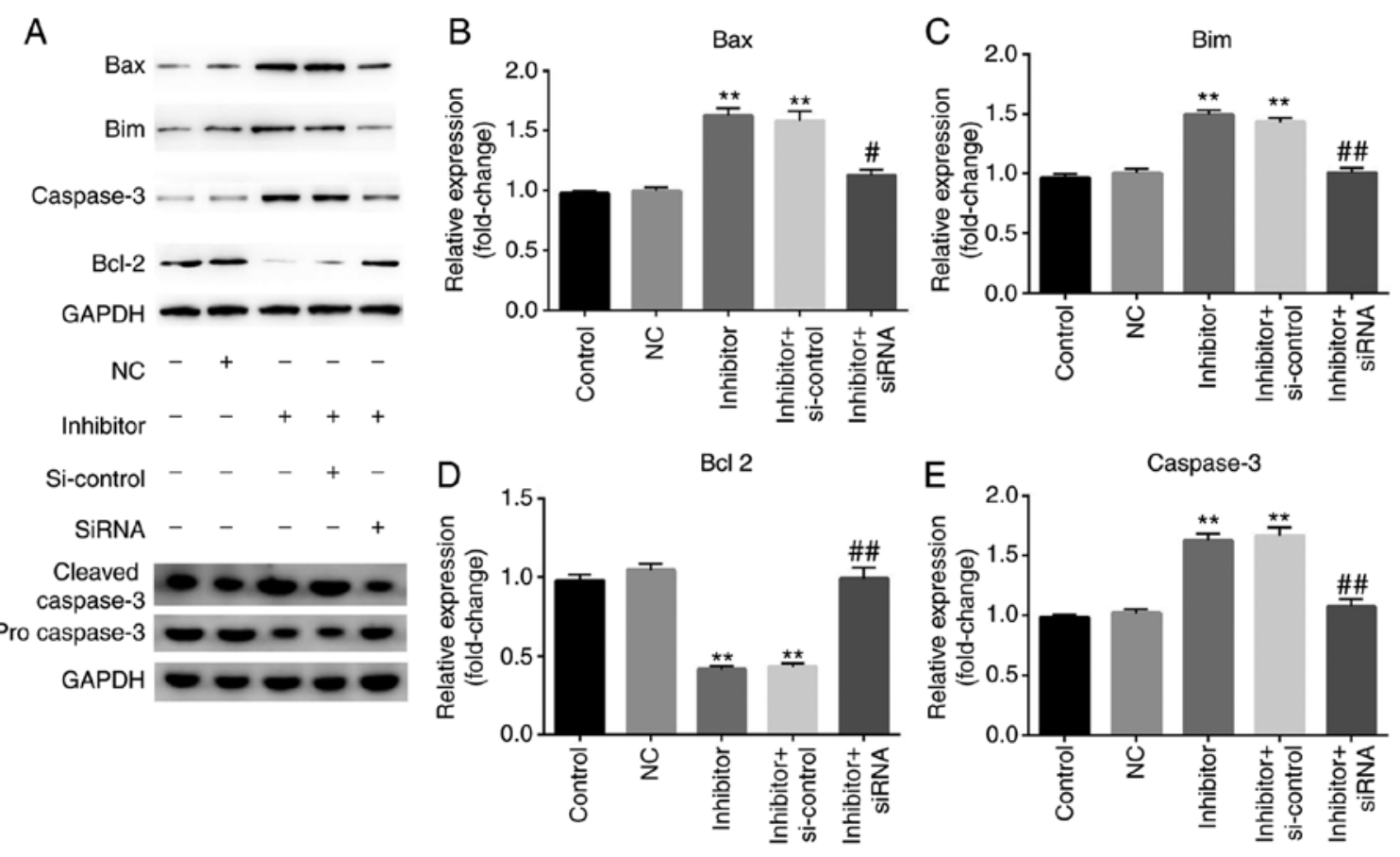

Figure 4. Effect of miR-25-3p downregulation on the expression level of Bim and apoptosis-associated molecules in NP cells. NP cells were transfected with inhibitor, NC, inhibitor + si-control or miR-25-3p inhibitor + inhibitor + siRNA for $48 \mathrm{~h}$. (A) A western blot assay was used to detect the protein expression of Bim and apoptosis-associated molecules such as Bcl-2, Bax, cleaved caspase-3 and caspase-3. Reverse transcription-quantitative PCR was used to detect the relative mRNA expression of (B) Bax, (C) Bim, (D) Bcl-2 and (E) caspase-3. Control, NP cells without any treatment; NC, NP cells transfected with the NC of miR-25-3p inhibitor; inhibitor, NP cells transfected with miR-25-3p inhibitor; control-siRNA, NP cells transfected with control-siRNA; inhibitor + si-control, NP cells transfected with miR-25-3p inhibitor and control-siRNA; inhibitor + siRNA, NP cells transfected with miR-25-3p inhibitor and Bim-siRNA. ${ }^{* *} \mathrm{P}<0.01$ vs. control; ${ }^{\#} \mathrm{P}<0.5,{ }^{\# \#} \mathrm{P}<0.01$ vs. inhibitor + si-control. miR, microRNA; NP, nucleus pulposus; NC Bim, Bcl-2 interacting mediator of cell death, negative control; si, small interfering.

system, with serious socioeconomic consequences (22-24). At present, due to work and family reasons (25), the incidence of
IDD is increasing, particularly in China. There are numerous studies focusing on the etiology of IDD, such as genetics (26), 

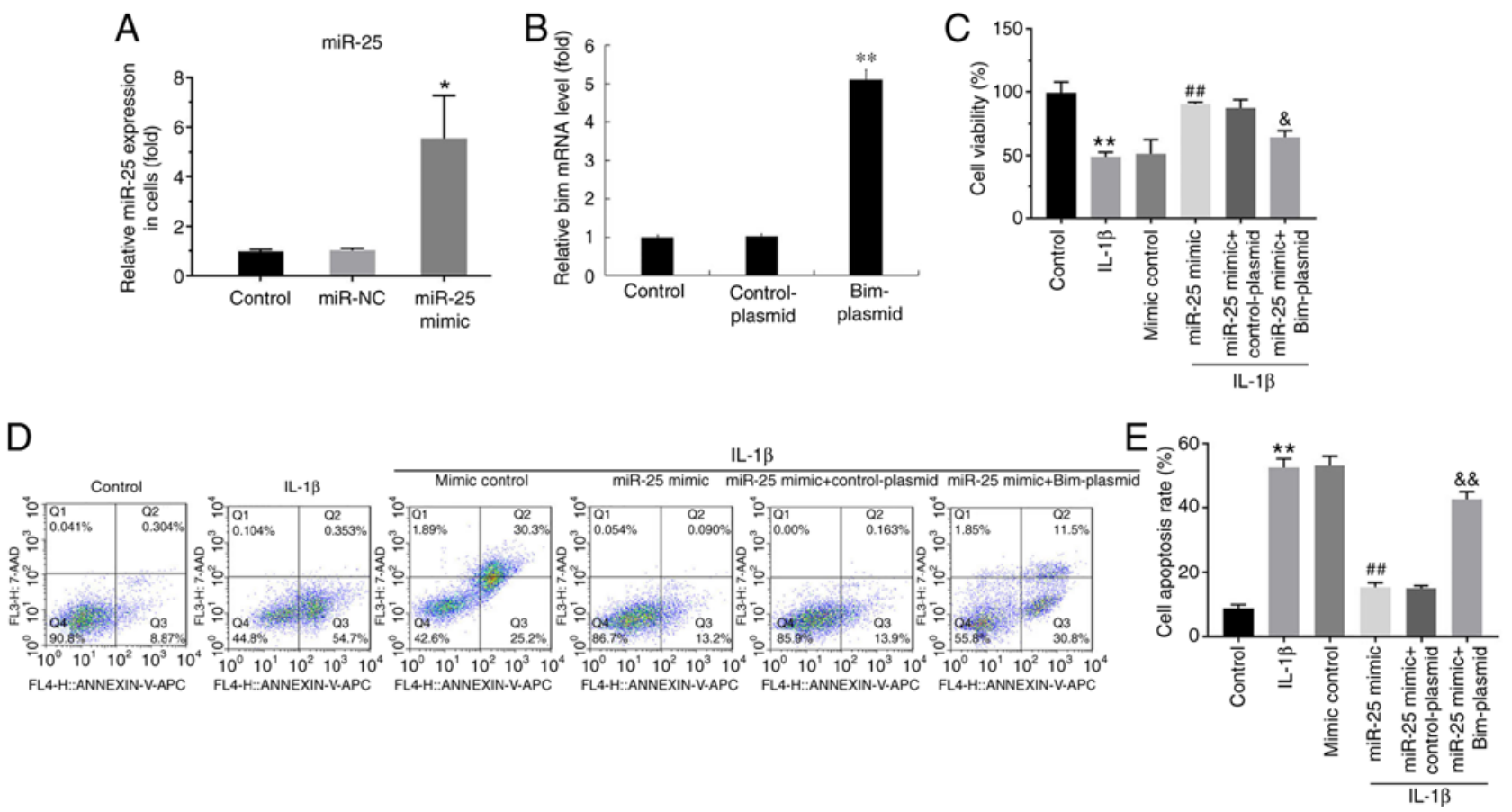

Figure 5. Effect of miR-25-3p on the proliferation and apoptosis of IL-1 $\beta$-induced NP cells. NP cells were transfected with miR-25-3p mimic, mimic control, miR-25-3p mimic + control-plasmid or miR-25-3p mimic + Bim-plasmid for $48 \mathrm{~h}$. Then, NP cells were treated with $10 \mathrm{ng} / \mathrm{ml} \mathrm{IL}-1 \beta$ for $24 \mathrm{~h}$. (A) The level of miR-25-3p in NP cells was detected using RT-qPCR. (B) The mRNA level of Bim in NP cells was detected using RT-qPCR. (C) Cell Counting Kit-8 assay detected the viability of NP cells transfected with miR-25-3p mimic, mimic control, miR-25-3p mimic + control-plasmid or miR-25-3p mimic + Bim-plasmid for $48 \mathrm{~h}$ and treated with $10 \mathrm{ng} / \mathrm{ml} \mathrm{IL-1 \beta}$ for $24 \mathrm{~h}$. (D) Flow cytometry assay and (E) analysis measured the apoptosis of NP cells transfected with miR-25-3p mimic, mimic control, miR-25-3p mimic + control-plasmid or miR-25-3p mimic + Bim-plasmid for $48 \mathrm{~h}$ and treated with $10 \mathrm{ng} / \mathrm{ml} \mathrm{IL}-1 \beta$ for $24 \mathrm{~h}$. ${ }^{*} \mathrm{P}<0.05 \mathrm{and}$ ${ }^{* *} \mathrm{P}<0.01$ vs. control; ${ }^{* \#} \mathrm{P}<0.01$ vs. IL-1 $\beta$; ${ }^{\circledR} \mathrm{P}<0.05$ and ${ }^{\& \&} \mathrm{P}<0.01$ vs. IL-1 $\beta+$ miR-25 mimic. miR, microRNA; NP, nucleus pulposus; IL, interleukin; RT-qPCR, reverse transcription-quantitative PCR; Bim, Bcl-2 interacting mediator of cell death.

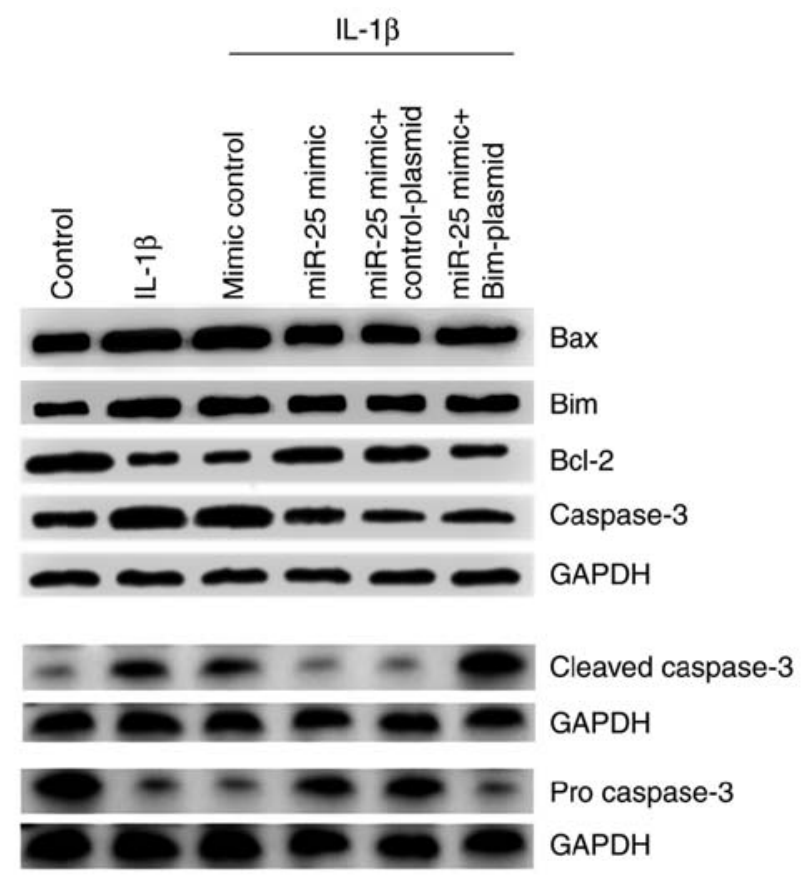

Figure 6. Effect of miR-25-3p on the expression level of Bim and apoptosis-associated molecules in IL-1 $\beta$-induced NP cells. NP cells were transfected with miR-25-3p mimic, mimic control, miR-25-3p mimic + control-plasmid or miR-25-3p mimic + Bim-plasmid for $48 \mathrm{~h}$. Then, NP cells were treated with $10 \mathrm{ng} / \mathrm{ml} \mathrm{IL}-1 \beta$ for $24 \mathrm{~h}$ and a western blot assay was used to detect the protein expression of Bim and apoptosis-associated molecules such as Bcl-2, Bax, cleaved caspase-3 and caspase-3. miR, microRNA; $\mathrm{NP}$, nucleus pulposus; IL, interleukin; Bim, Bcl-2 interacting mediator of cell death. mechanical load (27) and environmental factors (28); however, the pathology of IDD is not fully understood.

A previous study demonstrated that abnormal expression of miRNA-140 is associated with degenerative diseases such as osteoarthritis, which is characterized by similar pathological changes to those in IDD (29). In addition, miRNAs have gained considerable attention as regulators of gene expression and play important roles in the prevention and treatment of IDD $(30,31)$. It has been reported that TNF- $\alpha$ is a key pro-inflammatory cytokine, which not only has important roles in the inflammatory microenvironment of cancer and Mycobacterium tuberculosis infection (32), but also plays a critical role in IDD via its effects on NP cell apoptosis (33).

Previous research studies have demonstrated that several miRNAs are dysregulated in IDD, including miR-21, miR-10b, miR-640 and miR-27 (34-37). miR-200c is upregulated in degenerative NP tissues (38). In the present study, miR-25-3p was downregulated in degenerated NP cells. As expected, IDD-associated markers such as ACAN, collagen I, collagen II and SOX-9 were highly expressed in degenerated NP cells. A number of studies have shown that the great majority of miRNAs play an important role in their biological function by binding to their target gene (9-11).

Bim is located in the outer mitochondrial membrane and belongs to the pro-apoptotic Bcl-2 family, which contributes to TNF- $\alpha$-induced apoptotic signaling events $(39,40)$. Bim is closely associated with the development and treatment of autoimmune diseases, degenerative diseases and tumors. Previous studies have demonstrated that Bim is a target gene 
for multiple miRNAs $(41,42)$. Previous studies have shown that Bim is a putative miR-24 target $(43,44)$. One study suggested that miR-24 regulates hepatocyte apoptosis by suppressing Bim (43). In the present study, the dual luciferase reporter assay indicated that Bim was the target for miR-25-3p. Next, to investigate the effect of miR-25-3p on cell proliferation and apoptosis, normal NP cells were transfected with miR-25-3p inhibitor, NC, miR-25-3p inhibitor + si-control or miR-25-3p inhibitor + siRNA. The results demonstrated that transfection of miR-25-3p inhibitor could decrease cell proliferation, induce cell apoptosis and increase the expression of Bim, Bax, cleaved caspase- 3 and caspase- 3 and reduce Bcl- 2 and pro-caspase- 3 expression in NP cells.

Finally, an IDD in vitro cell model was established by treating normal NP cells with $10 \mathrm{ng} / \mathrm{ml} \mathrm{IL-1} \beta$ for $24 \mathrm{~h}$. Then, the effects of miR-25-3p on IL-1 $\beta$-treated NP cells were investigated. The results indicated that miR-25-3p upregulation enhanced IL-1 $\beta$-reduced NP cell viability and reduced IL-1 $\beta$-induced NP cell apoptosis. miR-25-3p upregulation decreased IL-1 $\beta$-enhanced expression of Bim, Bax, cleaved caspase- 3 and caspase- 3 , and increased IL-1 $\beta$-reduced expression of Bcl-2 and pro-caspase-3. Notably, all the effects of miR-25-3p upregulation on NP cells were reversed by the Bim-plasmid.

Taken together, these results indicated that miR-25-3p was downregulated in IDD and it was involved in the development of IDD through regulating NP cell proliferation, apoptosis and ECM deposition by targeting Bim. The current study may have provided new insights for the development of novel therapeutic strategies for IDD. However, this is a preliminary study on miR-25 in IDD. In order to verify the role of miR-25 in IDD, further experiments are needed. For example, the expression of miR-25 in human IDD samples needs to be detected and the role of miR-25/Bim in human NP cells should be investigated. The association between the expression of $\mathrm{miR}-25 / \mathrm{Bim}$ and the clinicopathological features of patients with IDD needs to be explored. In addition, the effect of miR-25 on IDD should be studied in vivo. These topics will be investigated in the future.

\section{Acknowledgements}

Not applicable.

\section{Funding}

No funding received.

\section{Availability of data and materials}

The analyzed data sets generated during the present study are available from the corresponding author on reasonable request.

\section{Authors' contributions}

ZZ contributed to study design, data collection, statistical analysis, data interpretation and manuscript preparation. JZ, YY, KZ and RuW contributed to data collection and statistical analysis. RaW contributed to data collection, statistical analysis and manuscript preparation. All authors read and approved the final version of the manuscript.

\section{Ethics approval and consent to participate}

The current study was approved by the Animal Ethics Committee of the No. 903 Hospital of People's Liberation Army (approval no. IRB SOP/01.03/01.1).

\section{Patient consent for publication}

Not applicable.

\section{Competing interests}

The authors declare that they have no competing interests.

\section{References}

1. Tang P, Gu JM, Xie ZA, Gu Y, Jie ZW, Huang KM, Wang JY, Fan SW, Jiang XS and Hu ZJ: Honokiol alleviates the degeneration of intervertebral disc via suppressing the activation of TXNIP-NLRP3 inflammasome signal pathway. Free Radic Biol Med 120: 368-379, 2018.

2. Wu D, Zheng C, Wu J, Huang R, Chen X, Zhang T and Zhang L: Molecular biological effects of weightlessness and hypergravity on intervertebral disc degeneration. Aerosp Med Hum Perform 88: 1123-1128, 2017.

3. Huang Y, Jiang T, Chen J, Yin GY and Fan J: Effects of kartogenin on the attenuated nucleus pulposus cell degeneration of intervertebral discs induced by interleukin- $1 \beta$ and tumor necrosis factor- $\alpha$. Int J Mol Med 41: 749-756, 2018.

4. Viguet-Carrin S, Roux JP, Arlot ME, Merabet Z, Leeming DJ, Byrjalsen I, Delmas PD and Bouxsein ML: Contribution of the advanced glycation end product pentosidine and of maturation of type I collagen to compressive biomechanical properties of human lumbar vertebrae. Bone 39: 1073-1079, 2006.

5. Vergroesen PP, Kingma I, Emanuel KS, Hoogendoorn RJ, Welting TJ, van Royen BJ, van Dieën JH and Smit TH: Mechanics and biology in intervertebral disc degeneration: A vicious circle. Osteoarthritis Cartilage 23: 1057-1070, 2015.

6. Mellis D and Caporali A: MicroRNA-based therapeutics in cardiovascular disease: screening and delivery to the target. Biochem Soc Trans 46: 11-21, 2018.

7. Ganju A, Khan S, Hafeez BB, Behrman SW, Yallapu MM, Chauhan SC and Jaggi M: miRNA nanotherapeutics for cancer. Drug Discov Today 22: 424-432, 2017.

8. Long H, Wang X, Chen Y, Wang L, Zhao Mand Lu Q: Dysregulation of microRNAs in autoimmune diseases: Pathogenesis, biomarkers and potential therapeutic targets. Cancer Lett 428: 90-103, 2018.

9. Ro S, Park C, Young D, Sanders KM and Yan W: Tissue-dependent paired expression of miRNAs. Nucleic Acids Res 35: 5944-5953, 2007.

10. Mallory AC and Vaucheret H: MicroRNAs: Something important between the genes. Curr Opin Plant Biol 7: 120-125, 2004.

11. Garzon R, Calin GA and Croce CM: MicroRNAs in cancer. Annu Rev Med 60: 167-179, 2009.

12. Xu JY, Yang LL, Ma C, Huang YL, Zhu GX and Chen QL: miR-25-3p attenuates the proliferation of tongue squamous cell carcinoma cell line Tca8113. Asian Pac J Trop Med 6: 743-747, 2013.

13. Fei Q and Ethell DW: Maneb potentiates paraquat neurotoxicity by inducing key Bcl-2 family members. J Neurochem 105: 2091-2097, 2008

14. Bouillet P, Purton JF, Godfrey DI, Zhang LC, Coultas L, Puthalakath H, Pellegrini M, Cory S, Adams JM and Strasser A: $\mathrm{BH} 3$-only Bcl-2 family member Bim is required for apoptosis of autoreactive thymocytes. Nature 415: 922-926, 2002.

15. Li Y, Deutzmann A and Felsher DW: BIM-mediated apoptosis and oncogene addiction. Aging (Albany NY) 8: 1834-1835, 2016.

16. Guo Y, Schoell MC and Freeman RS: The von Hippel-Lindau protein sensitizes renal carcinoma cells to apoptotic stimuli through stabilization of BIM(EL). Oncogene 28: 1864-1874, 2009. 
17. Baysan A, Yel L, Gollapudi S, Su H and Gupta S: Arsenic trioxide induces apoptosis via the mitochondrial pathway by upregulating the expression of Bax and Bim in human B cells. Int J Oncol 30: 313-318, 2007.

18. Bouillet P, Cory S, Adams J and Strasser A: Role of BH3-only protein Bim in autoimmune and degenerative diseases. Arthritis Res Ther 5 (Suppl 3): S19, 2003.

19. Issy AC, Castania V, Castania M, Salmon CE Nogueira-Barbosa MH, Bel ED and Defino HL: Experimental model of intervertebral disc degeneration by needle puncture in Wistar rats. Braz J Med Biol Res 46: 235-244, 2013.

20. Bayne K: Revised guide for the care and use of laboratory animals available. American physiological society. Physiologist 39: 199, 208-211, 1996.

21. Livak KJ and Schmittgen TD: Analysis of relative gene expression data using real-time quantitative PCR and the 2(-Delta Delta C(T)) method. Methods 25: 402-408, 2001.

22. Juniper M, Le TK and Mladsi D: The epidemiology, economic burden, and pharmacological treatment of chronic low back pain in France, Germany, Italy, Spain and the UK: A literature-based review. Expert Opin Pharmacother 10: 2581-2592, 2009.

23. Phillips C, Main C, Buck R, Aylward M, Wynne-Jones G and Farr A: Prioritising pain in policy making: The need for a whole systems perspective. Health Policy 88: 166-175, 2008.

24. Waddell G: Low back pain: A twentieth century health care enigma. Spine (Phila Pa 1976) 21: 2820-2825, 1996.

25. Zhang YG, Sun Z, Zhang Z, Liu J and Guo X: Risk factors for lumbar intervertebral disc herniation in Chinese population: A case-control study. Spine (Phila Pa 1976) 34: E918-E922, 2009.

26. Kalichman L and Hunter DJ: The genetics of intervertebral disc degeneration. Associated genes. Joint Bone Spine 75: 388-396, 2008.

27. Walter BA, Korecki CL, Purmessur D, Roughley PJ, Michalek AJ and Iatridis JC: Complex loading affects intervertebral disc mechanics and biology. Osteoarthritis Cartilage 19: 1011-1018, 2011.

28. Battié MC and Videman T: Lumbar disc degeneration: Epidemiology and genetics. J Bone Joint Surg Am 88 (Suppl 2): S3-S9, 2006.

29. Miyaki S, Nakasa T, Otsuki S, Grogan SP, Higashiyama R, Inoue A, Kato Y, Sato T, Lotz MK and Asahara H: MicroRNA-140 is expressed in differentiated human articular chondrocytes and modulates interleukin-1 responses. Arthritis Rheum 60: 2723-2730, 2009.

30. Wang HQ, Yu XD, Liu ZH, Cheng X, Samartzis D, Jia LT, Wu SX, Huang J, Chen J and Luo ZJ: Deregulated mir-155 promotes Fas-mediated apoptosis in human intervertebral disc degeneration by targeting FAdd and caspase-3. J Pathol 225: 232-242, 2011.

31. Ji ML, Lu J, Shi PL, Zhang XJ, Wang SZ, Chang Q, Chen $\mathrm{H}$ and Wang C: Dysregulated miR-98 contributes to extracellular matrix degradation by targeting IL-6/StAt3 signaling pathway in human intervertebral disc degeneration. J Bone Miner Res 31: 900-909, 2016

32. Wibawa T, Pangemanan L, Rachmawaty FJ, Rintiswati N, Mustofa and Soesatyo MH: Isoniazid (INH) treatment of INH-resistant Mycobacterium tuberculosis inhibits infected macrophage to produce TNF-alpha. Southeast Asian J Trop Med Public Health 45: 1107-1113, 2014.
33. Wang XH, Hong X, Zhu L, Wang YT, Bao JP, Liu L, Wang F and Wu XT: Tumor necrosis factor alpha promotes the proliferation of human nucleus pulposus cells via nuclear factor- $\kappa \mathrm{B}, \mathrm{c}-\mathrm{Jun}$ N-terminal kinase, and p38 mitogen-activated protein kinase. Exp Biol Med (Maywood) 240: 411-417, 2015.

34. Yu X, Li Z, Shen J, Wu WK, Liang J, Weng X and Qiu G: MicroRNA-10b promotes nucleus pulposus cell proliferation through RhoC-Akt pathway by targeting HOXD10 in intervetebral disc degeneration. PLoS One 8: e83080, 2013.

35. Liu H, Huang X, Liu X, Xiao S, Zhang Y, Xiang T, Shen X, Wang $G$ and Sheng B: miR-21 promotes human nucleus pulposus cell proliferation through PTEN/AKT signaling. Int J Mol Sci 15: 4007-4018, 2014.

36. Dong W, Liu J, Lv Y, Wang F, Liu T, Sun S, Liao B, Shu Z and Qian J: miR-640 aggravates intervertebral disc degeneration via NF- $\kappa$ B and WNT signalling pathway. Cell Prolif 52: e12664, 2019.

37. Liu G, Cao P, Chen H, Yuan W, Wang J and Tang X: MiR-27a regulates apoptosis in nucleus pulposus cells by targeting PI3K. PLoS One 8: e75251, 2013.

38. Cheng X, Zhang L, Zhang K, Zhang G, Hu Y, Sun X, Zhao C, Li H, Li YM and Zhao J: Circular RNA VMA21 protects against intervertebral disc degeneration through targeting miR-200c and X linked inhibitor-of-apoptosis protein. Ann Rheum Dis 77: 770-779, 2018.

39. Concannon CG, Tuffy LP, Weisová P, Bonner HP, Dávila D, Bonner C, Devocelle MC, Strasser A, Ward MW and Prehn JH: AMP kinase-mediated activation of the $\mathrm{BH} 3$-only protein Bim couples energy depletion to stress-induced apoptosis. J Cell Biol 189: 83-94, 2010

40. Kaufmann T, Jost PJ, Pellegrini M, Puthalakath H, Gugasyan R, Gerondakis S, Cretney E, Smyth MJ, Silke J, Hakem R, et al: Fatal hepatitis mediated by tumor necrosis factor TNFalpha requires caspase- 8 and involves the $\mathrm{BH} 3$-only proteins Bid and Bim. Immunity 30: 56-66, 2009.

41. Sur S, Steele R, Shi X and Ray RB: miRNA-29b inhibits prostate tumor growth and induces apoptosis by increasing Bim expression. Cells 8: 1455, 2019.

42. Labi V, Peng S, Klironomos F, Munschauer M, Kastelic N, Chakraborty T, Schoeler K, Derudder E, Martella M, Mastrobuoni G, et al: Context-specific regulation of cell survival by a miRNA-controlled BIM rheostat. Genes Dev 33: 1673-1687, 2019.

43. Feng Z, Li Z, Zhu D, Ling W, Zheng L, Pu L and Kong L: Mir-24 regulates hepatocyte apoptosis via BIM during acute liver failure. Am J Transl Res 9: 4925-4935, 2017.

44. Pan LJ, Wang X, Ling Y and Gong H: MiR-24 alleviates cardiomyocyte apoptosis after myocardial infarction via targeting BIM. Eur Rev Med Pharmacol Sci 21: 3088-3097, 2017.

This work is licensed under a Creative Commons Attribution-NonCommercial-NoDerivatives 4.0 International (CC BY-NC-ND 4.0) License. 